03

\title{
Экспериментальное исследование пленочного кипения недогретой воды методом градиентной теплометрии
}

\author{
(C) С.З. Сапожников, В.Ю. Митяков, А.В. Митяков, В.В. Субботина \\ Санкт-Петербургский политехнический университет Петра Великого, Санкт-Петербург, Россия \\ ๑ E-mail: subbotina.vv@edu.spbstu.ru
}

Поступило в Редакцию 16 ноября 2018 г.

В окончательной редакции 19 декабря 2018 г.

Принято к публикации 19 декабря 2018 г.

\begin{abstract}
Предложено качественное описание процесса кипения недогретой жидкости, полученное при помощи метода градиентной теплометрии. Разработанный метод позволил впервые измерить плотность теплового потока при пленочном кипении на торце цилиндра, погруженного в недогретую воду. Представлены кривые изменения плотности теплового потока во времени. Получена связь плотности теплового потока и коэффициента теплоотдачи.
\end{abstract}

DOI: 10.21883/PJTF.2019.06.47490.17594

Кипение недогретой жидкости на высокотемпературных поверхностях осуществляется во многих отраслях промышленности, преимущественно в энергетике и металлургии, а также в электронике. Во всех работах, представленных ранее, реализован косвенный анализ плотности теплового потока и коэффициента теплоотдачи (КТО), основанный на измерениях температуры, давления, толщины паровой пленки и на оптических методах [1-5]. Значения искомых величин получены из решения некорректной обратной задачи теплопроводности.

В экспериментах прикладной направленности традиционно используются нагретые образцы в форме цилиндра, при создании физических моделей [6] - в форме шара; в последнем случае снижаются концевые эффекты.

В настоящей работе задача впервые решается методом градиентной теплометрии, развиваемым в Санкт-Петербургском политехническом университете Петра Великого [7]. Градиентная теплометрия основана на использовании гетерогенных градиентных датчиков теплового потока (ГГДТП).

Метод позволяет напрямую измерить плотность теплового потока и вычислить КТО по известной разности температур между поверхностью образца и жидкостью.

Искусственно-анизотропная структура ГГДТП приводит к появлению поперечной составляющей вектора теплового потока и порождает поперечный эффект Зеебека; в нормальном к вектору теплового потока направлении формируется термоэдс, пропорциональная плотности теплового потока,

$$
E_{0}=S_{0} A q
$$

где $S_{0}-$ вольт-ваттная чувствительность ГГДТП $[\mathrm{mV} / \mathrm{W}], A$ - площадь ГгдТП в плане $\left[\mathrm{m}^{2}\right], q-$ плотность теплового потока $\left[\mathrm{W} / \mathrm{m}^{2}\right]$.

Вольт-ваттная чувствительность ГГДТП $S_{0}$ зависит от температуры. Градуировка датчиков проводилась на стенде, обеспечивающем рабочую температуру в пределах 293-823 К и уточнялась „по месту монтажа“ при пленочном кипении насыщенной воды, когда стабильный КТО определяется апробированной формулой Лабунцова и Гомелаури [8]:

$$
\alpha=0.32 \sqrt{\frac{\lambda^{2} g\left(\rho^{\prime}-\rho^{\prime \prime}\right) C}{v}} \sqrt{\frac{T_{s}}{T_{f}}} .
$$

Относительная неопределенность градуировки находилась в пределах 7-12\%.

Низкая постоянная времени ГГДТП $\left(10^{-8}-10^{-9} \mathrm{~s}\right)$ делает их практически безынерционными. Серая поверхность датчика позволяет определять интегральный тепловой поток (с учетом радиационной составляющей).

В работе использованы ГГДТП из композиции сталь $12 \mathrm{X} 18 \mathrm{H} 9 \mathrm{~T}+$ никель с термостойкостью до $1300 \mathrm{~K}$ и вольт-ваттной чувствительностью $0.4-0.6 \mathrm{mV} / \mathrm{W}$.

Экспериментальный стенд (рис. 1) состоит из вертикальной проходной муфельной печи, образца с ГГДТП, резервуара объемом $10 \mathrm{dm}^{3}$, измерительно-вычислительного комплекса (ИВК) и видеокамеры.

Образец выполнен в виде цилиндра из латуни Л68 диаметром $25 \mathrm{~mm}$ и длиной $150 \mathrm{~mm}$. На нижнем торце в выборке глубиной $0.7 \mathrm{~mm}$ закреплен термостойким компаундом ГГДТП и вмонтирован спай термопары ТХА (рис. $1, a)$. На верхней части выполнено резьбовое соединение со стержнем-держателем. Все провода выведены на образующую цилиндра через наклонные отверстия и подключены к ИВК. Керамические трубки обеспечили тепловую защиту и электрическую изоляцию всех проводников. Для контроля температуры ГГДТП использовалась трехпроводная схема коммутации (рис. 1, b).

Температура воды в резервуаре измерялась термопарой ТХА; в ходе опыта она имела практически постоянное значение $294 \mathrm{~K}$.

Регистрация сигналов ГГДТП и термопар осуществлялась при помощи ИВК National Instruments 

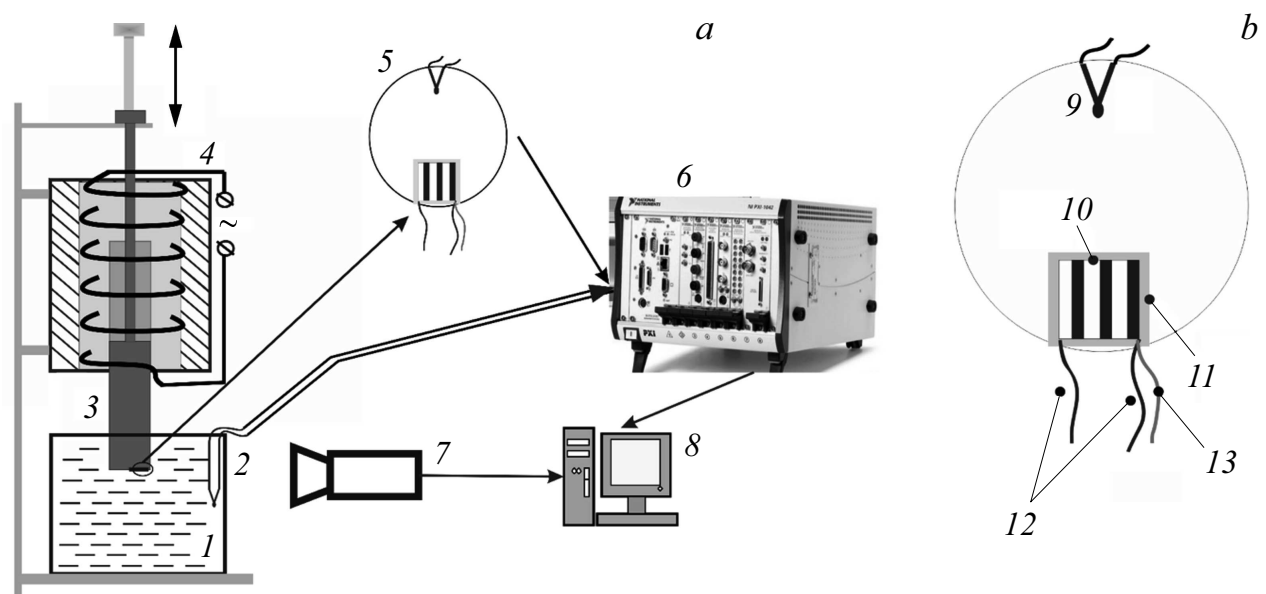

Рис. 1. Экспериментальная установка $(a)$ и размещение датчиков на образце $(b) .1-$ резервуар с водой, 2 - термопара ТХА для измерения $T_{f}, 3$ - образец из латуни Л68, 4 - проходная муфельная печь, 5 - торец образца с датчиками, 6 - ИВК National Instruments, 7 - высокоскоростная камера Casio Exilim EX-FH20, 8 - компьютер, 9 - термопара ТХА для измерения $T_{w}, 10-$ ГГДТП, 11 - слюда, 12 - алюмель, 13 - хромель.

(NI PXI-6289) с частотой $10^{6} \mathrm{~Hz}$. Последующая обработка происходила в программных средах LabView и Origin. Визуализацию опыта обеспечивала высокоско-
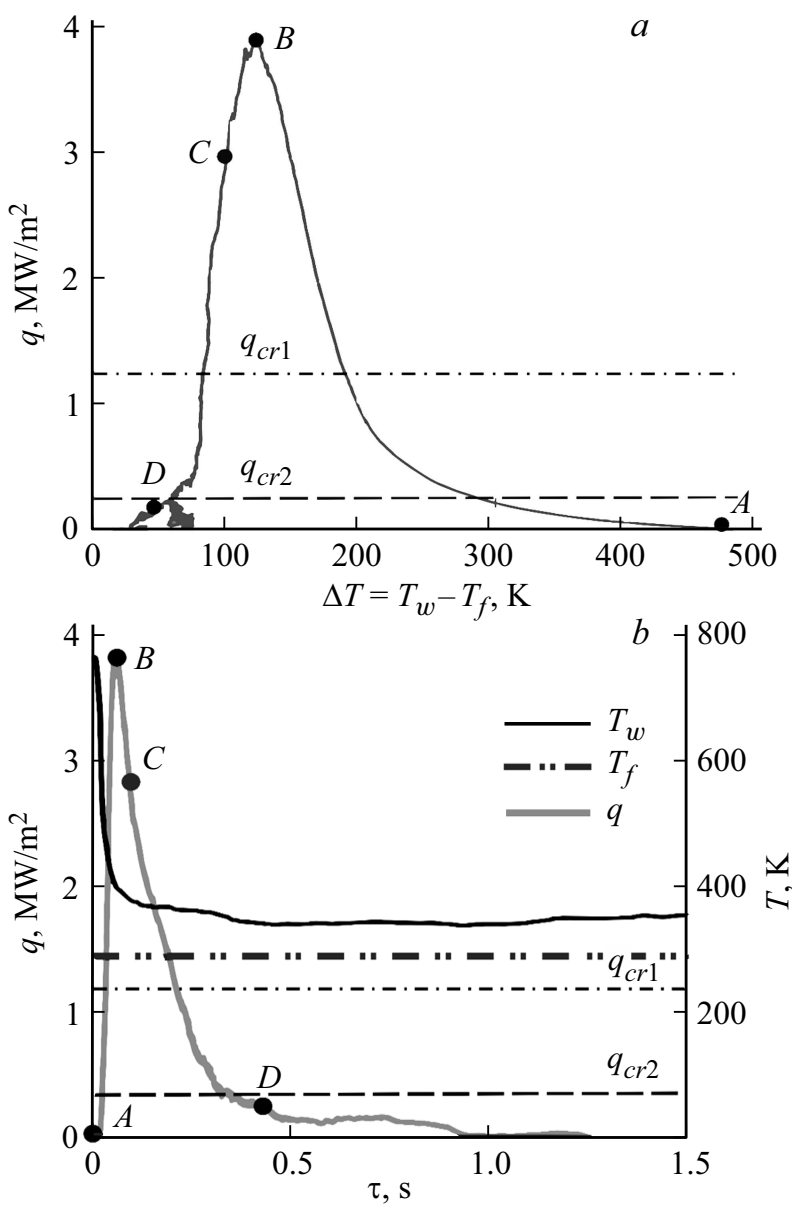

Рис. 2. Кривые охлаждения образца. $a-$ зависимость плотности теплового потока от температурного напора, $b-$ временны́е термо- и теплограммы.

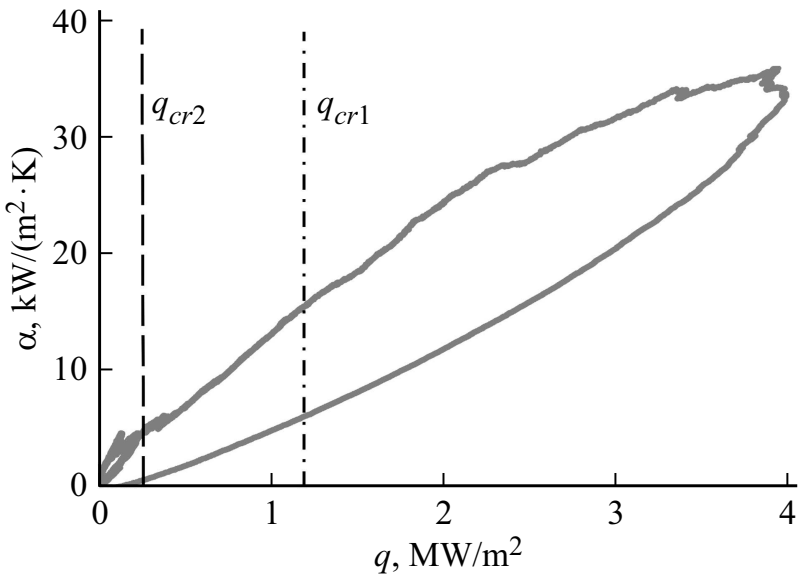

Рис. 3. Связь плотности теплового потока и КТО.

ростная камера Casio Exilim EX-FH20 со скоростью съемки $1000 \mathrm{fps}$; затем видеокадры сопоставлялись с результатами градиентной теплометрии.

Нагретый до $794 \mathrm{~K}$ образец вертикально погружался в холодную воду на глубину $30 \mathrm{~mm}$. При первичном контакте с водой плотность теплового потока резко увеличивается (рис. 2, участок $A B$ ). Нагрев и испарение воды в пристенном слое ведут к образованию паровой пленки, предотвращению контакта между твердой и жидкой фазами и, как следствие, появлению экстремума на графике (точка $B$ ). Дальнейшее уменьшение плотности теплового потока (участок ВС) связано с низким КТО в паровой пленке (рис. 3). Срыв паровой пленки начинается с острой кромки цилиндра (чаще всего с места монтажа ГГДТП) и затем распространяется на весь образец. Переход в пузырьковый режим происходит на участке $C D$.

На рис. 3 показана зависимость КТО от плотности теплового потока. Максимальная плотность теплового 
потока $\left(4 \mathrm{MW} / \mathrm{m}^{2}\right)$ вчетверо превышает первую критическую плотность при кипении насыщенной воды.

В эксперименте подтверждены работоспособность и информативность градиентной теплометрии при исследовании кипения. Доказана интенсификация теплообмена при пленочном кипении недогретой жидкости. Именно прямое измерение (а не вычисление плотности теплового потока) благодаря методу градиентной теплометрии обеспечивает отечественный приоритет в этой области.

В дальнейших работах появится возможность экспериментально исследовать теплообмен при кипении в различных геометрических условиях, при разных режимах и для различных жидкостей.

\section{Список литературы}

[1] Ягов В.В., Забиров А.Р., Канин П.К., Денисов М.А. // Инж.физ. журн. 2017. Т. 90. № 2. С. 287-298.

[2] Пузина Ю.Ю., Ковалев С.А., Кубриков К.Г. // Вестн. МЭИ. 2013. № 4. C. 41-46.

[3] Kenning D.B.R. // Int. J. Heat Fluid Flow. 2004. V. 25. P. 209 222.

[4] Gong S., Ma W., Wang C., Mei Y., Gu H. // Int. J. Heat Mass Transfer. 2015. V. 90. P. 636-644.

[5] Emery T.S., Jaikumar A., Raghupathi P., Joshi I., Kandlikar S.G. // Int. J. Heat Mass Transfer. 2018. V. 122. P. 1053-1073.

[6] Sher I., Harari R., Reshef R., Sher E. // Appl. Therm. Eng. 2012. V. 36. P. 219-226.

[7] Сапожников С.3., Митяков В.Ю., Митяков А.В. Основы градиентной теплометрии. СПб.: Изд-во Политехн. ун-та, 2012. $203 \mathrm{c}$.

[8] Лабунцов Л.А., Гомелаури А.В. // Тр. МЭИ. 1976. В. 310. C. $50-58$. 